\title{
Helicobacter pylori Infection in Pediatric Patients: Update on Diagnosis and Eradication Strategies
}

\author{
Kallirroi Kotilea $^{1} \cdot$ Nicolas Kalach $^{2} \cdot$ Matjaž Homan $^{3} \cdot$ Patrick Bontems $^{1}$ (I)
}

Published online: 22 May 2018

(C) Springer International Publishing AG, part of Springer Nature 2018
Patrick Bontems

patrick.bontems@huderf.be

1 Department of Pediatric Gastroenterology, Université Libre de Bruxelles, Hôpital Universitaire des Enfants Reine Fabiola, Brussels, Belgium

2 Department of Paediatrics, Saint Antoine Paediatric Hospital, Saint Vincent de Paul Hospital, Groupement des Hôpitaux de l'Institut Catholique de Lille (GHICL), Catholic University of Lille, Lille, France

3 Department of Gastroenterology, Hepatology and Nutrition, University of Ljubljana, University Children's Hospital, Ljubljana, Slovenia

\section{Key Points}

The gastric microbiota has changed in recent decades, and there is a parallel between economic development and a lower prevalence of Helicobacter pylori.

Some evidence links the decreasing prevalence of this bacterium in childhood and the increasing incidence of immunological disorders, although in the long term, infection with $H$. pylori can provoke ulcer disease and gastric cancer.

Indications for eradication of this infection in childhood have been updated and adequate management of symptomatic children requires an upper gastrointestinal endoscopic exam with mucosal biopsy samples for histology and culture or PCR (polymerase chain reaction) as a minimum.

Eradication regimens must be tailored to susceptibility testing, and it is mandatory to develop these tests based on culture or PCR technique worldwide.

\section{Introduction}

Helicobacter pylori, a spiral and microaerophilic bacterium, is one of the most prevalent human pathogens and the major cause of chronic gastritis, peptic ulcer disease, gastric adenocarcinoma, and mucosa-associated lymphoid 
tissue (MALT) lymphoma in children and in adults [1]. The prevalence of $H$. pylori infection, generally acquired during childhood and persisting throughout life if untreated, is related mainly to socioeconomic status and living conditions (crowded and poor hygiene). The persistence of bacterium exposure leads to gastritis and other severe complications. Virulence factors, host gastric mucosal factors [2] and the patient's environment are associated with the clinical outcome of $H$. pylori infection. While becoming rare in the more developed areas of the world, preventive (vaccine) and therapeutic strategies are currently being developed, especially in Asia, to decrease the incidence of $H$. pylori and of chronic gastritis in an attempt to prevent further severe complications later in life.

A few months ago, the new version of the recommendations for the management of $H$. pylori infections in children in Europe and in North America was published [3]. These guidelines are an update of the former version [4], based on relevant scientific data published between 2009 and 2014. The impact of more recent publications on the guidelines is discussed in this article, which covers the changes in epidemiology, risk factors, relevant diagnostic procedures, and clinical approach to patient management.

\section{Epidemiology}

A recent review with reports from 62 countries estimates that more than half the world's population is still infected with H. pylori. This means that, based on regional prevalence estimates, there were approximately 4.4 billion individuals with $H$. pylori infection worldwide in 2015 [5]. In children, a comprehensive review and meta-analysis of original pediatric studies from 2011 to 2016 performed on healthy children estimated an overall seroprevalence rate of $33 \%$ [95\% confidence interval (CI) 27-38] [6]. Seroprevalence increased with age while both parameters decreased with higher income. Model estimates of crosssectional direct detection studies in asymptomatic children indicated a prevalence of $37 \%$ (95\% CI 30-44). The model estimate based on cross-sectional studies in symptomatic children was only mildly higher when compared with asymptomatic children, with an estimated prevalence of $39 \%$ (95\% CI 35-43). In the same study, a review of information available from seven cohort studies concluded that infection rates in healthy children under 5 years of age were still between 20 and $40 \%$ in high-income countries and between 30 and $50 \%$ in upper-middle income countries, indicating that the country of birth plays a role in infection prevalence. Higher rates of infection $(>40 \%)$, as determined by cross-sectional studies, are predominantly seen in low- or low-to-middle-income areas (or in countries with severe income inequality) [6]. However, huge variations in prevalence can be observed between countries with similar living conditions. This can be observed in Europe, for example, where the prevalence of $H$. pylori infection remains high in Spain and Portugal, although the levels of sanitation and of economic development have risen in recent decades and are comparable to other European countries where the prevalence of infection is significantly lower. Similar variations from country to country can also be seen in Asia, which cannot be fully explained by only looking at the level of development [7].

The prevalence of $H$. pylori infection in both children and adults is decreasing in developed countries. One study from Iceland involved 205 children aged 7-17 years and found only $3.4 \%$ of infection [8]. Furthermore, the prevalence was $2.6 \%$ among children when both parents were born in a low prevalence country compared with $17 \%$ among those with at least one parent born in a high prevalence area $(p=0.026)$. This confirms results obtained in Belgium some years ago [9]. In Poland, the prevalence of $H$. pylori infection in 8661 symptomatic and untreated children from 2000 to 2013 assessed by culture was $16.1 \%$. The highest prevalence of infection was found in the year $2000(23.1 \%)$ and the lowest in $2010(8.9 \%)$ [10]. However, in Latvia, no evidence of a fall in prevalence in children was found during the last 10 years and the prevalence determined by stool antigen test was $15.5 \%$ [11].

The prevalence is also decreasing in some countries in Asia and in the Middle East. Indeed, studies from Japan have shown a considerable fall in $H$. pylori prevalence in childhood. One study from a high gastric cancer incidence area found only 85 of $1765(4.8 \%)$ students aged 13-15 years to be infected [12] and, in another study, the prevalence in school children aged $12-15$ years was $3.1 \%$ [13]. The same fall has been observed in Iran, where former reports of $H$. pylori infection indicated a global prevalence of more than $85 \%$ and recent ones estimated an overall prevalence of $54 \%$, with a prevalence of $42 \%$ in children [14]. Similar trends are seen in China where, in Hangzhou, the infection rates in three age groups (3-6, $7-11$, and $12-17$ years) were $14.8,20.2$, and $25.8 \%$, respectively. The overall prevalence decreased from 21.6 to $17.2 \%$ between 2007 and 2014 [15]. In contrast, in Vietnam, the seroprevalence in 1094 subjects from 278 households remained stable at $51.4 \%$ in adults and $41.4 \%$ in children [16].

Conversely, the prevalence of $H$. pylori infection remains high in newly arrived refugees attending the migrant health service in South Australia, where 922 adults and children were screened in a cross-sectional study using a monoclonal stool antigen test. H. pylori infection was detected in 198 of them (21.5\%), almost 1.5 times that of the Australian population's estimate when both adults and 
children are included [17]. A systematic review involving 28 studies described the prevalence of $H$. pylori among migrants. In all but two, the prevalence was similar to or lower than in their country of origin but higher than in their country of destination. Second and later generations of migrants had a lower prevalence than the first generation [18]. The prevalence of $H$. pylori, assessed by a $H$. pylori stool antigen (HpSA) test, among 240 asymptomatic children living in a rural setting in sub-Saharan Africa, was $14.2 \%$ [19]. The prevalence of H. pylori assessed by polymerase chain reaction (PCR) on oral swabs in 162 asymptomatic Mexican children was 13\% [20].

\section{Pathogenesis}

Virulence factors, gastric mucosal host factors, and environmental factors are associated with the clinical outcome of $H$. pylori infection. The main bacterial virulence factors include adhesins [blood-group antigenbinding adhesin (BabA), sialic acid-binding adhesin (SabA)], vacuolating cytotoxin $\mathrm{VacA}$, and the products of the cag pathogenicity island ( $\operatorname{cag} \mathrm{P} \mathrm{AI})$. There are geographic differences between $\operatorname{cag} A, v a c A$ status and $H$. pylori-related diseases [21]. In Western countries, infection with a vacA s1 strain is more common in patients with peptic ulcer than in those with chronic gastritis alone. However, in Asian countries, the association between vacA diversity and clinical outcome is not well established [22]. The integrity of the gastric mucosa is mainly affected by the interaction of virulence products (VacA and CagA) with the proteins of the intercellular junctions, which alters the stability of the complex E-cadherin/ $\beta$-catenin with consequences of structure, functional modification, and cellular transformation [23].

Few studies evaluating parameters of the immune response in children (except for antibody determination) have been performed, but recently a great interest in this field has arisen. The persistence of $H$. pylori colonization is critical for the development of complications and represents the strongest risk factor for gastric adenocarcinoma and MALT lymphoma [24]. Consequently, the clinical manifestations of $H$. pylori infection complications occur predominantly in adults rather than in children. Gastric inflammation in children colonized by $H$. pylori differs from adults by a reduction in polymorphonuclear and mononuclear cell infiltration, decreasing the incidence of gastroduodenal ulceration in comparison with adults [25].

Understanding the immuno-biological basis for the reduced inflammatory response in $H$. pylori-infected children, particularly in comparison with that of infected adults, is critical for identifying mechanisms by which the host suppresses the neoplastic potential of $H$. pylori infection in children [26]. Inflammation in children has been shown to be less than that of adults, indicating a downregulation in immune response to infection in children [2]. Moreover, the sequence analysis revealed that the bacteria isolated from infected children and adults might have similar cagA and vacA gene profiles. The difference in bacterial strains and common virulence factors were not the cause of the lower level of inflammation in infected children compared with adults $[2,26]$.

H. pylori infection in children is associated with a high $T_{\text {reg }}$ response, as well as a low $T_{\mathrm{h}} 1$ and $T_{\mathrm{h}} 17$ response [26-28]. However, H. pylori-specific $T_{\mathrm{h}} 17 / T_{\mathrm{h}} 1$ detection in chronically infected adults may reveal that the initial regulatory response is progressively lost [29]. Hence, $T_{\mathrm{h}} 1$, $T_{\mathrm{h}} 17$, and $T_{\text {reg }}$ results may imply gastric mucosal response to H. pylori [30].

Recently, a cross-sectional study performed on 126 children showed that the presence of the CT and CT + TT genotypes of IL-6 190C/T, a G allele of IL-6 $572 \mathrm{G} / \mathrm{C}$ polymorphism, the GA and AA genotypes of TNF- $\alpha 308 \mathrm{G} /$ A polymorphism, and the genotype II of ACE I/D polymorphism were associated with $H$. pylori infection, while the CC genotype of IL-6 174G/C polymorphism was scarcely encountered in children with $H$. pylori infection. Therefore, those polymorphisms may contribute to the pathogenesis of $H$. pylori gastritis [31]. In a study from Brazil, DNA samples were obtained from 285 gastric biopsies of pediatric patients. H. pylori was detected by PCR, whereas PCR-RFLP (restriction fragment length polymorphism) was used to characterize the $-251(\mathrm{~T}>\mathrm{A})$ polymorphism of IL-8. The results showed that the IL8-251 A allele may be an important risk factor for the development of gastric disease when associated with $H$. pylori infection [32]. Another study from Poland, analyzing gastric biopsies of 78 children to investigate the expression of innate immunity components and cytokines in the gastric mucosa, concluded that $H$. pylori infection was characterized by (a) $T_{\mathrm{h}} 1$ expression profile, (b) lack of mRNA overexpression of natural immunity receptors, and (c) strong anti-inflammatory activities in the gastric mucosa, possibly resulting from increased activity of antiinflammatory M2 macrophages. This may explain the mildly inflammatory gastric inflammation often observed among $H$. pylori-infected children [33].

The role of gastric microbiota in H. pylori pathogenesis has also been studied in a cohort study including 86 children and adults with and without chronic $H$. pylori gastritis performed in Santiago, Chile. Gastric microbiota was analyzed by $16 \mathrm{~S}$ rRNA bacterial gene sequencing. The findings indicated that $H$. pylori infection in children, not adults, is associated with changes in the commensal microbiota and an increased gastric $\mathrm{T}_{\text {reg }}$ response. The gastric microbiota is an underappreciated potential factor 
that could be involved in promoting a more tolerant antiinflammatory gastric environment in early life, possibly through the induction of $\mathrm{T}_{\text {reg }}$ responses that down-regulate gastric inflammation in H. pylori-infected children [34].

\section{Clinical Manifestations}

\subsection{Digestive Manifestations}

Although less frequent in children than in adults, H. pyloriassociated gastro-duodenal ulcers are without doubt responsible for abdominal pain and upper gastrointestinal bleeding [2]. In adults, there is evidence from randomized clinical trials and meta-analyses that a proportion of infected patients with dyspepsia, in the absence of esophagitis and of gastro-duodenal erosions/ulcers, are improved after successful $H$. pylori eradication [35-37]. In contrast, trials in children investigating the role of $H$. pylori in dyspepsia are not conclusive because they are uncontrolled [38-45], of poor quality, or do not include sufficient patients to draw conclusions [46]. No clinical manifestations, and especially not recurrent abdominal pain (RAP), have been shown to be specific to $H$. pylori infection in children. Data from adults can therefore not be extrapolated to children. For that reason, testing only for $H$. pylori in children with dyspepsia (Rome IV criteria [47]) is not acceptable clinical management as stated in the recent guidelines [3]. Other diagnoses have to be excluded and, if an eradication treatment is proposed, the patients and the parents must be informed that $H$. pylori gastritis is probably not the cause of the symptoms [3, 48].

The more recent publications are also not in favor of an implication of $H$. pylori gastritis in dyspepsia or other abdominal complaints in children, in the absence of ulcer disease. Among 1558 children aged 6-13 years in Iran, 145 children with RAP, according to the Apley and Naish criteria, were compared with 145 age-matched healthy controls recruited from the same area. There was no significant difference between the RAP symptoms in $H$. pylori-positive children versus $H$. pylori-negative ones [49]. Similar results were obtained in a prospective observational study in Brazil. Among 240 Brazilian children with dyspepsia, $52 \%$ being infected by $H$. pylori, there was no significant association between $H$. pylori infection and gastrointestinal manifestations, either RAP or pain characteristics [50].

To evaluate a possible association between functional abdominal pain disorders fulfilling Rome III criteria, considered as the patient group, and fecal calprotectin level in age-/sex-matched healthy controls and $H$. pylori-infected children, a total of 56 patients (27 with functional dyspepsia) and 56 controls were enrolled. H. pylori infection was detected in 17 of 56 cases (30.4\%) and 4 of 56 controls
$(7.1 \%, p=0.003)$. The median fecal calprotectin level was the same in control patients as in patients with gastritis. The authors concluded that fecal calprotectin is not a predictor of H. pylori gastritis [51].

Erosive esophagitis and gastro-duodenal ulcers/erosions should be searched for in dyspeptic patients as these diagnoses are not rare findings at endoscopy and are not always related to $H$. pylori infection. Infection should be treated in the case of ulcer disease to prevent recurrence of lesions. Over a period of 7 years, 1026 children underwent an upper-gastrointestinal endoscopy. Peptic ulcers and erosions were found in $7.2 \%$ patients (ulcers in $5.1 \%$ and erosions in $2.1 \%$ ). H. pylori infection was found in 27 patients (45.8\%) [52]. Erdemir et al. recently reported an association between infection and gastrointestinal diseases such as gastritis and peptic ulcers in $H$. pylori-infected children in Turkey. Of these children, $14.9 \%$ were malnourished. Bodyweight and height $Z$ scores were significantly lower in $H$. pylori-seropositive children. Serum leptin, ghrelin, and IGF-1 levels were not associated with H. pylori IgG seropositivity [53]. However, in 178 Mexican schoolchildren, $H$. pylori-infected children had lower concentrations of leptin and obestatin than those without infection, after adjustment by age, gender, and BMI. These results suggest that $H$. pylori infection affects the levels of hormones implicated in regulating appetite and energy homeostasis [54]. These data must be confirmed by other concordant studies before ascertaining an effect of $H$. pylori infection in children on the hormones implicated in regulating appetite and energy homeostasis.

\subsection{Extra-Digestive Manifestations}

Iron deficiency is a frequent health condition, particularly in the youngest children, mainly due to the high requirements associated with rapid growth and low iron content of dietary intake aggravated by a low bioavailability, particularly for non-heme iron in food [55, 56]. Four metaanalyses have concluded that $H$. pylori infection is a causative factor in the development of iron deficiency anemia. Several pathways have been implicated, including decrease in absorption of dietary iron due to hypochlorhydria, gastrointestinal blood loss, and enhanced uptake and sequestration of iron by the bacteria [57]. Some intervention studies have shown a beneficial effect of $H$. pylori eradication on iron deficiency anemia, but some methodological flaws limit the value of these studies [58-62]. Impaired iron absorption due to $H$. pylori infection certainly has more clinical consequences in poor resource settings with poor quality of food intake, and fewer effects in European or North American settings. For the latter reason and the lower prevalence of infection in developed countries, testing for $H$. pylori infection as part of the initial 
investigation in children with iron deficiency anemia was not recommended in the last ESPGHAN/NASPGHAN consensus [3]. However, in regions with high prevalence of H. pylori infection, that recommendation may not be applicable. Following the consensus, infection should only be searched for in refractory anemia, when other causes have been ruled out. The term 'refractory' is, unfortunately, not clearly defined. In our practice, the term is used in case of failure of or recurrence after intravenous supplementation.

Chronic immune thrombocytopenic purpura (cITP) is an autoimmune disease characterized by autoantibody-mediated platelet destruction lasting more than 6 months $[63,64]$. Some reports in children and in adults suggest that when investigating causes of cITP, H. pylori infection should be considered. Indeed, partial or even complete remission of thrombocytopenia has been reported in some patients after $H$. pylori eradication [65-69].

The role of $H$. pylori infection on failure to thrive (FTT) or on children's growth remains controversial. The existing evidence is based on observational studies $(n=48)$ and suggests that $H$. pylori infection may adversely influence children's growth. Scarce evidence exists on the effect of H. pylori eradication on children's skeletal growth and weight gain, but there is an indication that $H$. pylori eradication may benefit nutritional status [70]. The possible effects of $H$. pylori infection on growth were examined and the results support that $H$. pylori infection is inversely associated with childhood growth trajectory [71]. However, this study was carried out in Ethiopian children and the results cannot be generalized to children in developed countries, such as Europe and North America. Further prospective multicenter studies remain required.

In endemic areas such as China, H. pylori infection rates seemed extraordinarily more frequent in children with Henoch-Schonlein purpura (HSP), particularly those with abdominal manifestations. However, the causality between H. pylori infection and HSP was not confirmed, and the pathogenic mechanism is still unclear [72]. Chronic $H$. pylori infection has been involved in obstructive sleep apnea syndrome (OSAS), responsible for sleep-disordered breathing (SDB) in children [73]. The association between H. pylori infection and type I diabetes mellitus (T1DM) in children is controversial. In a case-control study, the $H$. pylori status was assessed in 80 diabetic children versus 80 non-diabetic children. $H$. pylori infection was significantly higher in diabetic versus non-diabetic patients, $p=0.030$. The authors concluded that T1DM children are more at risk of acquiring an $H$. pylori infection [74]. In contrast, in another prospective case-control study, there was no significant difference of $H$. pylori infection rate between diabetic patients and controls [75].

\subsection{Atopic Manifestations}

Experimental studies in mice suggest that an infection early in life results in a stimulation of regulatory $\mathrm{T}$ cells and protection against immunological hypersensitivity diseases such as asthma [76]. Some epidemiological evidence has been reported recently. Indeed, $H$. pylori prevalence in Western countries has been declining simultaneously with increases in childhood asthma and allergic diseases. In the Netherlands, 3797 subjects were enrolled in a multi-ethnic population-based cohort. The $H$. pylori infection rate was 8.7, and $29.2 \%$ of them were CagA-positive. A child's colonization with a CagA-negative $H$. pylori strain was associated with an increased risk of asthma prevalence, but this was significantly higher in European versus nonEuropean children. Furthermore, only H. pylori-positive children with an $H$. pylori-negative mother had an increased risk of asthma, accounting for $3.4 \%$ of the asthma risk [77]. The levels of $\mathrm{sIgG}$ and sIgG4 to foods were found to be highly variable in a study by Czaja-Bulsa et al. [78], who suggest that one responsible factor could be the presence of an inflammatory gastrointestinal disease. They found in a cohort of 200 children that serum concentrations of wheat and rice $\mathrm{IgG}$ and $\mathrm{IgG} 4$ were significantly elevated in children with celiac disease, H. pylori, and wheat allergy compared with healthy control children.

The prevalence of $H$. pylori in children with confirmed celiac disease $(\mathrm{CD})$ was compared with non-CD children referred for endoscopy. H. pylori infection was present in $11.4 \%$ of CD versus $50 \%$ of non-CD children, $p<0.001$. This result raises the question whether development of $H$. pylori infection confers protection against CD [79]. However, this result needs confirmation before suggesting that celiac disease is really less likely to be found in patients with $H$. pylori infection.

\section{Diagnosis}

Infection with $H$. pylori can be diagnosed by either invasive tests performed on biopsy samples obtained during an upper gastrointestinal endoscopy (culture, histology, rapid urease test, and PCR) or by non-invasive tests $\left({ }^{13} \mathrm{C}\right.$-urea breath test and stool antigen test). However, the goal of clinical investigation is to detect the cause of the child's symptoms. Since current evidence indicates that $H$. pylori infection is not associated with symptoms in the absence of peptic ulcer disease, performing a non-invasive test to detect infection and treat if the test is positive is not warranted. Therefore, this 'test and treat' strategy based on non-invasive methods of diagnosis for $H$. pylori infection in children is not and has never been recommended. Children with symptoms suggestive of pathological 
conditions of the upper digestive tract, such as dyspepsia, should be evaluated by upper-gastrointestinal endoscopy [48]. The diagnosis of $H$. pylori infection should be based on either (a) positive culture or (b) histopathology ( $H$. pylori-positive gastritis) plus at least one other positive biopsy-based test (rapid urease test or PCR) [3]. Yang [80] recently updated the differences between children and adults in the diagnosis of $H$. pylori infection. The author confirmed that nodular gastritis is a common endoscopic finding of childhood $H$. pylori infection (44-67\% in children vs $0.19-13 \%$ in adults). The main histopathologic findings are that acute active inflammation (infiltration of neutrophils) is less prominent in children compared with adults, while chronic inflammation (infiltration of lymphocytes and plasma cells) is more prominent in children than adults. Lash and Genta [81] carried out a very large study on gastric biopsy stained with histochemical stains only compared with those stained with labeled anti- $H$. pylori antibodies. They reported a dramatic improvement in detection of $H$. pylori infection using upfront immunehistochemical staining.

Evaluation of the outcome of an eradication treatment should be based on validated non-invasive tests, (i.e., ${ }^{13} \mathrm{C}$ UBT and monoclonal stool antigen test) performed at least 2 and 4 weeks after proton pump inhibitor (PPI) therapy and antibiotic therapy completion (to avoid false-negative results). These tests can also be used for epidemiological studies. Children younger than 6 years have a higher rate of false-positive urea breath tests [82]. The reported performance of the urea breath test for detection of $H$. pylori infection in a recent study, in comparison with biopsybased histologic examination in 60 children, is low with a sensitivity of $76.2 \%$ and a specificity of $69.2 \%$ in this age group [83]. Many pitfalls were underlined to explain these poor results. Patient compliance, consumption of PPIs and/ or antibiotics or host-organism interaction varying among ethnic backgrounds can affect the urease activity, as previously reported in Turkish and German children. Therefore, stool antigen tests using an ELISA technique with a monoclonal antibody are regarded as more convenient in young children than the urea breath test [83]. Furthermore, in another study that used a real-time PCR, it was shown that stool ELISA is a reliable method in characterizing $H$. pylori dynamics in apparently healthy children. Persistent infection was only detected in $2.7 \%$ of 36 children [84].

Low bacterial density can be a cause of false-negative results in up to half of scoped children. Indeed, a gastric biopsy-based quantitative PCR (qPCR) for the detection of H. pylori infection and the identification of clarithromycinresistant strains in children was evaluated in 62 children with infection and 341 children without infection. A composite 'reference method' was used: a child was considered infected by H. pylori when culture was positive or, in case of negative culture, when both histology and a rapid urease test were positive. The qPCR showed a bacterial load $\geq 10$ copies per milliliter when culture, histology, and rapid urease test were all positive (29/31 children) versus $<10$ copies per milliliter when culture, histology, and rapid urease test were all negative (25/31 children). Grades 2 and 3 histological gastritis were associated with a bacterial load $\geq 10$ copies per milliliter for $28 / 35$ children versus $27 / 27$ with grade $0-1<10$ copies per milliliter. $H$. pylori $\mathrm{qPCR}$ positivity was shown to be a more sensitive test than the routine culture, histology, or rapid urease test alone, allowing detection of low bacterial loads [85].

Antibody-based tests (IgG, IgA) for H. pylori in serum, whole blood, urine, or saliva in the clinical setting are not recommended for clinical decisions and not encouraged for epidemiological purposes [3]. Some recent publications suggest, however, that recent serological tests are more reliable in children. A French study assessed a quick, noninvasive, one-step immuno-chromatographic $H$. pylori stool antigen test in 158 children. This test showed $91.3 \%$ sensitivity, $97 \%$ specificity, 30.84 positive likelihood ratio and 0.09 negative likelihood ratio. The test accuracy was $96.2 \%$. Therefore, this test can be considered as consistent, reliable, quick, and specific for detecting $H$. pylori in children [86]. One hundred Egyptian children with a mean age of 7.2 years referred for upper gastrointestinal endoscopy had biopsies and serum samples collected to detect IgG against $H$. pylori by ELISA in order to evaluate the accuracy of this test. The sensitivity, specificity, positive likelihood ratio, and negative likelihood ratio for the $\operatorname{IgG}$ antibody were $96.5,93 \%, 13.83$, and 0.038 , respectively [87]. Recently, an antibody test for detection of $H$. pylorispecific IgG by ELISA in urine was developed and tested in 806 junior and senior students in Japan. The results obtained showed $97.6 \%$ sensitivity, $96.5 \%$ specificity, $61.2 \%$ positive predictive value (PPV), and $99.9 \%$ negative predictive value (NPV) [88]. In another study, the same authors using $H$. pylori-specific IgG by ELISA in urine compared with serum $H$. pylori IgG-ELISA as the gold standard, reported sensitivity, specificity, PPV, and NPV for the rapid urine antibody test to be $85.7,100,100$, and $99.4 \%$, respectively [34]. Seo et al. [89] looked for correlations between anti-H. pylori $\operatorname{IgG}$ and $\operatorname{IgA}$ levels and the urease test, anti-CagA protein antibody, degree of gastritis, and age in 509 children stratified by age. They demonstrated that the anti-H. pylori IgG and IgA antibody titers were higher in the CagA-positive sera of children regardless of age, while $\operatorname{IgG}$ and $\operatorname{IgA}$ titers increased with chronic gastritis degree, active gastritis, H. pylori infiltration, urease test grade, and older age. In another retrospective study of 395 children referred for upper gastrointestinal endoscopy to evaluate epigastric pain, heartburn, and nausea or vomiting, the histology was positive for $H$. pylori 
infection in $13 \%$ and epigastric pain was documented in $87 \%$ of these patients. Compared with histology, the serology had a sensitivity of $88.4 \%$ and a specificity of $93.4 \%$, while the rapid urease test and the stool antigen test had sensitivities of 89.3 and $55.6 \%$ and specificities of 89.9 and $98.9 \%$, respectively [90].

The feasibility of using breath ammonia analysis based on off-axis cavity-enhanced absorption spectroscopy (OACEAS) with an external-cavity diode laser (ECL) was assessed for non-invasive diagnosis of $H$. pylori infection. Analyses were performed on 15 healthy volunteers as well as on 8 children and 19 adults with $H$. pylori infection. The ammonia concentrations for patients with $H$. pylori infection were significantly higher than those for healthy volunteers. The authors suggest that the breath ammonia measurement system has the potential for future use in easy, non-invasive diagnosis of $H$. pylori infection [91]. Other studies are needed, of course, to draw firm conclusions.

\section{Treatment}

Treatments targeting $H$. pylori infection consist of combinations of a PPI and several antimicrobial agents. It has been shown that treatment success must be over $90 \%$ in per-protocol analysis $[92,93]$ to prevent induction of secondary antimicrobial resistance, and reduce expensive and risky procedures required by rescue treatments. This goal is, however, rarely observed in pediatric trials and, in a recent meta-analysis, both a sequential regimen for 10 days and a triple regimen for 14 days, recommended in the last consensus guidelines, were successful in only 73.6 (435/ 591) and $71.7 \%$ (104/145), respectively [94], in the absence of antimicrobial susceptibility testing and compliance monitoring.

The reference treatment since the end of the 1990s has been the combination of two antibiotics (amoxicillin $50 \mathrm{mg} / \mathrm{kg} /$ day - maximum $2 \mathrm{~g}$ combined with either clarithromycin $15 \mathrm{mg} / \mathrm{kg} / \mathrm{day}$ - maximum $1 \mathrm{~g}$ or metronidazole $20 \mathrm{mg} / \mathrm{kg} /$ day-maximum $1 \mathrm{~g}$ ) and a PPI $(1 \mathrm{mg} /$ $\mathrm{kg} /$ day - maximum $40 \mathrm{mg}$ ) for 7 days in Europe and for 14 days in North America [95]. This triple therapy was given in two daily doses. The efficacy of this treatment has decreased over time due mainly to antimicrobial resistance and poor treatment compliance, but also to a shorter duration in Europe. The EHMSG consensus guidelines for the management of $H$. pylori infection in adults since 2012 [96] and in children since 2017 [3] now recommend a 14-day duration that increases the success rate by roughly $5 \%[97,98]$.

Due to decreased efficacy [99], especially if the susceptibility of strains to antibiotics is not known, other schemes have been proposed such as sequential treatment consisting of two successive 5-day treatment periods: amoxicillin $(50 \mathrm{mg} / \mathrm{kg} / \mathrm{day}$-maximum $2 \mathrm{~g})$ and PPI $(1 \mathrm{mg} / \mathrm{kg} / \mathrm{day}$-maximum $40 \mathrm{mg})$ twice daily, then metronidazole combination $(20 \mathrm{mg} / \mathrm{kg} / \mathrm{day}$-maximum $1 \mathrm{~g})$ and clarithromycin $(15 \mathrm{mg} / \mathrm{kg} /$ day-maximum $1 \mathrm{~g})$ with a PPI [100, 101]. The rationale for using this sequential treatment is that amoxicillin would reduce the bacterial burden and destroy the bacterial cell wall during the first 5 days. Subsequently, intracellular spread of clarithromycin could be increased and be more effective with fewer side effects than with a standard triple therapy [102]. However, this treatment is only truly efficient if compliance is optimal and if the strain is susceptible to both metronidazole and clarithromycin [103, 104]. Schwarzer et al. [103] evaluated the efficacy of a sequential treatment for 10 days and showed that the eradication rate was only satisfactory in case of strains susceptible to both clarithromycin and metronidazole $(115 / 134,86 \%)$ in Europe. In case of resistance to clarithromycin or to metronidazole, the eradication rate was lower $(45 / 62,73 \%)$, and even lower in case of double resistance $(2 / 7,29 \%)$. Besides antimicrobial resistance, intake of $<90 \%$ of prescribed drugs was a significant independent factor affecting eradication rate. This was confirmed by Kotilea et al. [104]. The sequential treatment has been abandoned in adults as it has been shown to be less efficient than a concomitant quadruple therapy and a triple therapy tailored to antimicrobial susceptibility [105]. Data on concomitant quadruple therapy in children are lacking and this treatment can therefore not be recommended for children currently.

Bismuth-based quadruple treatment in adults has also shown superior efficacy to conventional triple therapy [106]. The dosage of bismuth salt used in an adult quadruple scheme is higher than the one accepted in children [107, 108] and the use of tetracyclines is contraindicated in children.

The therapeutic options that can currently be recommended in children, as well as their advantages and disadvantages, are shown in Table 1 and the indication for treatment is summarized in Table 2. The dosage of each drug we use in routine practice is given in Table 3. There are some differences with those published in the ESPGHAN/NASPGHAN guidelines because we want to avoid under-dosage in some weight ranges. We have, however, no data showing that these dosages will give higher eradication rates compared with the previously published ones [3].

Antimicrobial susceptibility testing should be performed before prescribing an eradication treatment and this is now a formal recommendation of the ESPGHAN and NASPGHAN consensus guidelines [3]. Increasing antimicrobial resistance rates against clarithromycin emerged around 
Table 1 Currently recommended eradication regimens for Helicobacter pylori-infected children

\begin{tabular}{|c|c|c|}
\hline Treatment option & Duration & Comments \\
\hline PPI-AMO-CLA & 14 days & $\begin{array}{l}\text { Only if strain proved to be susceptible to CLA and AMO } \\
\text { Currently published data indicate that the target of } 90 \% \text { cannot be achieved } \\
\text { No risk of induction of MET resistance }\end{array}$ \\
\hline PPI-AMO-MET & 14 days & $\begin{array}{l}\text { Eradication rate probably lower than with CLA-containing triple therapy } \\
\text { Impact of MET resistance on success rate maybe limited } \\
\text { Can be proposed in case of double resistance (to CLA and to MET) }\end{array}$ \\
\hline PPI-CLA-MET & 14 days & $\begin{array}{l}\text { In case of allergy to AMO } \\
\text { Only if strain proved to be susceptible to CLA }\end{array}$ \\
\hline Sequential quadruple & 10 days & $\begin{array}{l}\text { Only if strain proved to be susceptible to CLA, MET, and AMO } \\
\text { Risk of induction of double resistance (to CLA and to MET) }\end{array}$ \\
\hline $\begin{array}{l}\text { Bismuth-based triple or } \\
\text { quadruple therapy }\end{array}$ & 10-14 days & $\begin{array}{l}\text { Difference between triple and quadruple is adjunction of PPI } \\
\text { Different bismuth salts can be proposed depending on local availability (subcitrate in Europe, } \\
\text { subsalicylate in the US) } \\
\text { Data for triple needs to be updated } \\
\text { Few data available for quadruple }\end{array}$ \\
\hline
\end{tabular}

Based on the last ESPGHAN/NASPGHAN consensus guidelines (Jones et al. 2017 [3])

$A M O$ amoxicillin, CLA clarithromycin, MET metronidazole, $P P I$ proton pump inhibitor

Table 2 Indication of eradication treatment for Helicobacter pylori-infected children

\begin{tabular}{ll}
\hline Clinical situations & Recommendation for treatment \\
\hline Incidental finding at endoscopy & May be considered after discussion with patient/parents \\
Ulcer (erosions) disease & Yes \\
Abdominal pain & No \\
Test and treat & No \\
Short stature & No \\
Iron deficiency anemia & No \\
Refractory iron deficiency anemia & May be considered \\
Chronic immune thrombocytopenic purpura & May be considered \\
\hline
\end{tabular}

Based on the last ESPGHAN/NASPGHAN consensus guidelines (Jones et al. 2017 [3])
1995 within Europe and was described initially in Brussels $[109,110]$ and in most countries since then. Political interventions to decrease the over-use of antibiotics resulted in a less frequent prescription of macrolides between 2000 and 2010 in Belgium and a concomitant decrease in resistance of $H$. pylori clinical isolates [111], but more recent data show a new increase in resistance in the Belgian population [112]. The resistance rate against metronidazole remains high but is usually stable, the resistance against quinolones is rapidly increasing and a lower susceptibility against amoxicillin (increased minimal inhibitory concentration) is observed in some places. Mixed infections may explain the failure of clarithromycin-containing regimens, although the phenotype, at culture, indicates that the strain is susceptible. The first description of mixed infection came from a microbiology laboratory in Brussels [110] and these data have been confirmed by others since then. The last publication on the subject, by Gościniak et al. [113], reported a very high rate of heteroresistance $(47 \%, 7 / 15)$ in children in Wroclaw, Poland.

Recent publications further support the high rate of antimicrobial resistance of clinical isolates. Some of these studies address the situation in Europe. Montes et al. [114] performed a longitudinal study of $H$. pylori-infected children referred for upper gastrointestinal endoscopy in Spain. Resistance to clarithromycin was 35 , and $17 \%$ to metronidazole. Eradication was lower using a triple therapy when the strains were resistant to one antimicrobial agent $(3 / 8$, $38 \%$ ) than when treatment was tailored to the susceptibility test $(48 / 61,79 \%)$, although even in the later scenario the $90 \%$ goal was not reached. Manfredi et al. [115] reported the evolution of antimicrobial resistance between the 1998-1999 and the 2011-2012 periods in Northern Italy. They observed an increase in resistance to clarithromycin 
Table 3 Fixed-dose drugs, according to the bodyweight of the child, to be used for eradication regimens for Helicobacter pylori infection in children

\begin{tabular}{llccc}
\hline Drug & Weight groups $(\mathrm{kg})$ & Morning dose $(\mathrm{mg})$ & Evening dose $(\mathrm{mg})$ & Corresponding dose range $(\mathrm{mg} / \mathrm{kg})$ \\
\hline Esomeprazole & $20-24$ & 20 & 10 & $1.2-1.5$ \\
& $25-34$ & 20 & 20 & $1.2-1.6$ \\
& $35-49$ & 40 & 20 & $1.2-1.7$ \\
& $>50$ & 40 & 40 & $<1.6$ \\
Amoxicillin & $20-24$ & 750 & 750 & $60-75$ \\
& $25-34$ & 1000 & 1000 & $60-80$ \\
& $35-49$ & 1500 & 1500 & $60-85$ \\
Clarithromycin & $20-24$ & 1500 & 1500 & $<60$ \\
& $25-34$ & 250 & 250 & $22-30$ \\
& $35-49$ & 500 & 250 & $20-28$ \\
Metronidazole & $>50$ & 500 & 500 & $<20$ \\
& $20-24$ & 500 & 500 & $20-25$ \\
& $25-34$ & 250 & 250 & $22-30$ \\
& $35-49$ & 500 & 250 & $20-28$ \\
\hline
\end{tabular}

(from 16 to $26 \%$ ) and a decrease of resistance to metronidazole (from 56 to $33 \%$ ). Resistance to amoxicillin remained low (2/141). Maleknejad et al. [116] estimated the resistance rate of $H$. pylori strains in Iran. Metronidazole resistance was $57 \%$, furazolidone $38 \%$, tetracycline $24 \%$, and clarithromycin $16 \%$. However, the sensitivity of the culture was low and these data need confirmation. Regnath et al. [117] reported the antimicrobial resistance rate in Southwest Germany during the period from 2002 to 2015. Overall resistance to metronidazole, clarithromycin, and rifampicin was $28.7,23.2$, and $13.3 \%$, respectively, while resistance to amoxicillin was rare $(0.8 \%)$. Simultaneous resistance to metronidazole and clarithromycin was observed for $7.7 \%$ of the isolates, and $2.3 \%$ were resistant to metronidazole, clarithromycin, and rifampicin. AguileraCorrea et al. [118] analyzed the resistance rate against clarithromycin and the genotype associated with the resistance: $\mathrm{A} 2142 \mathrm{G}$ or $\mathrm{A} 2143 \mathrm{G}$, the latter being the more frequent $(87.5 \%)$. Strains resistant to clarithromycin were found in $64 / 111(57.7 \%)$, but in 11 of the 64 a mixed infection was found with both susceptible and resistant strains to clarithromycin.

Some recent data on antimicrobial resistance are also available for Asia and the Middle East. The prevalence of resistance to antimicrobials in a large series of 1746 clinical isolates from the Southeast regions of China was reported by $\mathrm{Li}$ et al. The resistance rate was $16.4 \%$ to clarithromycin, $75.2 \%$ to metronidazole, $6.7 \%$ to levofloxacin, $0.06 \%$ to amoxicillin, and $0.06 \%$ to furazolidone.
Dual resistance to both clarithromycin and metronidazole was observed in $10.7 \%$ of children. Mahmoudi et al. [119] reported the resistance rate to antimicrobials in Teheran, Iran. Resistance was $22 \%$ to clarithromycin and $62.5 \%$ to metronidazole. Khoury et al. [120] reported the prevalence of secondary antimicrobial resistance in Haifa, Israel. In children, resistance was $42.5 \%$ to clarithromycin, $46.7 \%$ to metronidazole, and $5.1 \%$ to amoxicillin. No levofloxacin resistance was found. Ogata et al. [121] compared results of antimicrobial susceptibility tests performed by agar dilution (reference method), by $E$ test, and by disk diffusion. A good correlation was found between these techniques for metronidazole, clarithromycin, furazolidone, and tetracycline, but not for amoxicillin. They conclude that $E$ tests should be preferred instead of disk diffusion in daily routine. This is of major importance since an effort should be made to render susceptibility tests available everywhere.

Studies comparing the different therapeutic options in the pediatric population remain limited. However, a recent meta-analysis including 10 randomized studies showed that in 318 of $409(78 \%)$ children who received a sequential treatment, the infection was eradicated compared with 314 of $444(70.7 \%)$ in the triple therapy arm (RR 1.14, 95\% CI 1.06-1.23) [101]. Weiner and Shaoul [122] evaluated the efficacy of a triple therapy containing clarithromycin for 14 days as first-line treatment and containing metronidazole as rescue treatment. Antimicrobial susceptibility was not tested, and a comparison was made between those 
receiving the triple therapy alone and those receiving a probiotic. The eradication rate after first-line treatment was only 222/327 (67.9\%) and 42/66 (63.6\%) after second-line treatment. No significant difference was noted between the probiotic and the control group. Huang and Zhan [94] performed a meta-analysis of the randomized clinical trials comparing a sequential treatment for 10 days with triple therapies for 7-14 days. They concluded that the eradication obtained with a sequential treatment for 10 days is comparable to the one obtained with a triple therapy for 14 days but superior to a triple therapy for 10 or 7 days. However, the rate of eradication was lower than the expected goal and factors associated with treatment failure, antimicrobial susceptibility, and compliance were insufficiently investigated.

Some new eradication regimens have been tested recently. Ramos-Soriano and Black [123] described the efficacy of a novel regimen containing three antimicrobials: nitazoxanide, azithromycin, and cefixime for 7-10 days. They reported a success rate of 99/111 (89.2\%). These data have to be confirmed by other trials and in different settings. Esmaeili et al. [124] compared clarithromycin- and azithromycin-containing triple therapy for 10 days (azithromycin for 6 days) in Iran. They found no significant advantage of using azithromycin instead of clarithromycin and the eradication rate was only $38 / 60$ $(63.3 \%)$. Farahmand et al. [125] compared the efficacy of two triple therapies in Iran: one containing omeprazole, amoxicillin, and ciprofloxacin, and the second containing omeprazole, amoxicillin, and furazolidone. The eradication rate was high with the ciprofloxacin-containing regimen $(29 / 33,87.9 \%)$ and significantly lower with the furazolidone-containing one $(20 / 33,60.6 \%)$. Due to the low number of patients and the absence of antimicrobial susceptibility testing, these data need confirmation. Iwańczak et al. [126] compared the efficacy of a sequential regimen for 10 days with a clarithromycin-containing triple therapy and a metronidazole-containing therapy for 7 days. Eradication was observed in $18 / 23(78.2 \%)$ children with the clarithromycin-containing triple regimen, 18/23 (78.2\%) with the metronidazole-containing triple regimen, and 21/23 (91.3\%) with the sequential regimen. Failure of treatment was mainly associated with antimicrobial resistance: five in the clarithromycin-containing triple regimen, one in the metronidazole-containing triple regimen, and one in the sequential regimen. Kasiri et al. conducted a trial comparing two triple therapies for 14 days in Iran. Children were treated either with omeprazole, amoxicillin, and clarithromycin, or omeprazole, clarithromycin, and metronidazole. Eradication rates obtained with both treatments were close to $90 \%$ with no significant difference between them. These very good results contrast, however, with those obtained in most studies using the same treatment regimen. Butenko et al. [127] reported the eradication rates obtained in Slovenia with a tailored triple therapy for 7-14 days as well as antimicrobial susceptibility results. Results of eradication were obtained in 71 of the 107 children included and $61 / 71(85.9 \%)$ were successful. Resistance to clarithromycin was reported in $23.4 \%$, to metronidazole in $20.2 \%$, to levofloxacin in $2.8 \%$, and to amoxicillin in $1.0 \%$. Dual resistance to clarithromycin and metronidazole was found in $11.5 \%$.

\section{Probiotics}

The most commonly reported adverse events due to eradication therapies are diarrhea, nausea, and vomiting. Adverse events have significant physical and/or social impacts, and it has been shown that side effects were significantly associated with decreased compliance and treatment failure [104]. Therefore, there is the need for development of alternative treatment options for the $H$. pylori infection in pediatric patients.

The results of some pediatric studies suggest that standard eradication therapy supplemented with sufficient amounts of certain probiotic strains diminish the frequency of gastrointestinal adverse events. Saccharomyces boulardii was used as an adjuvant therapy to standard treatment eradication protocol in a prospective open study that included 90 infected children. The intervention group also treated with $S$. boulardii ( $250 \mathrm{mg}$ twice daily for 4 weeks) showed significant impact on the incidence of side effects [128]. The positive role of $S$. boulardii in reducing adverse effects was confirmed in a meta-analysis published by Szajewska et al. [129] although most of the studies were performed on adult populations. Five randomized controlled trials of good methodological quality involving 1307 patients were identified. Among them, 90 children were included. The daily dose of $S$. boulardii ranged from $500 \mathrm{mg}$ to $1000 \mathrm{mg}$ and the duration of the therapy was 2-4 weeks. Adverse effects were reported in $24.3 \%$ of patients in the control group treated with triple therapy compared with $12.9 \%$ of patients in the probiotic group. The risk of therapy-related diarrhea was statistically significantly lower in the probiotic group compared with the control group treated only with antibiotics and a PPI (5.6 vs $12.2 \%$, RR $0.47,95 \%$ CI $0.32-0.69$ ). The conclusions of the meta-analysis were that the concomitant use of $S$. boulardii with triple therapy moderately increases $H$. pylori eradication rates and decreases antibiotic-related adverse effects, especially diarrhea. In addition, Zhang et al. included 194 infected children in a recent probiotic study [130]. S. boulardii significantly decreased the incidence of diarrhea associated with standard $H$. pylori eradication therapy. Even if diarrhea developed, it was less severe and 
of shorter duration, and it was speculated that the consequence was a $10 \%$ higher eradication rate in the probiotic group. However, the main limitation of the study was that the majority of children were diagnosed with a less reliable serology test. The Gastrointestinal Symptom Rating Score was also lower in the group of children treated with $\mathrm{Lac}$ tobacillus reuteri in addition to triple therapy in comparison with the placebo group treated only with eradication therapy ( 3.2 vs $5.8, p<0.009$ ) [131]. The role of probiotic strains in increasing eradication rates is more doubtful. Lactobacillus casei [132] or Lactobacillus acidophilus and Bifidobacterium bifidum [133] added to triple therapy showed some beneficial effects in improving eradication rates.

Few meta-analyses attempting to draw conclusions regarding the role of probiotics in $H$. pylori treatment in children have been published [134-136]. Some of these studies suggest that probiotics added to $H$. pylori eradication treatment may reduce adverse effects and consequently improve efficacy. Unfortunately, the studies included in these meta-analyses use different probiotic strains in various concentrations, making it difficult to draw meaningful conclusions. To have more reliable conclusions regarding the positive effects of probiotics in $H$. pylori eradication regimens, additional pediatric studies with specific probiotic strains in sufficient amounts must be performed.

\section{Conclusions}

The prevalence of $H$. pylori infection, which persists over a lifetime if untreated and may lead to severe complications such as ulcer disease and gastric cancer, is declining in developed and in some emerging countries, especially in children. However, infection rates remain high in some regions and depend, in more developed ones, on the migration status of the family and on economic factors that should also be taken into account when defining national preventive strategies. New insights have been discovered concerning the lower mucosal immune response and the possible role of $H$. pylori in preventing immune disorders such as allergy. Indications for treatment of this infection and optimal regimens have been proposed by a recent consensus guideline as well as optimal diagnostic tests. However, the latest clinical series published have shown that the target of $90 \%$ eradication with first-line treatment may not be reached by these regimens and especially not if treatment is not tailored to antimicrobial susceptibility tests and if compliance is not optimal (>90\%). Improvement strategies, using the Deming circle, are still needed in regional centers to reach this goal. Eradication failure at first line results in a decreased chance of success with rescue therapy, induces secondary resistance to antimicrobials, causes expensive additional health expenditures, and exposes children to risks associated with additional procedures.

\section{Compliance with Ethical Standards}

Funding No sources of funding were used to prepare this review article.

Conflicts of interest PB is a member of the advisory board of Biocodex. KK, NK and MH have no conflicts of interest to declare.

\section{References}

1. Atherton JC. The pathogenesis of Helicobacter pylori-induced gastro-duodenal diseases. Annu Rev Pathol. 2006;1(1):63-96.

2. Bontems P, Aksoy E, Burette A, et al. NF- $\kappa B$ activation and severity of gastritis in Helicobacter pylori-infected children and adults. Helicobacter. 2014;19(3):157-67.

3. Jones NL, Koletzko S, Goodman K, et al. Joint ESPGHAN/ NASPGHAN guidelines for the management of Helicobacter pylori in children and adolescents (update 2016). J Pediatr Gastroenterol Nutr. 2017;64(6):991-1003.

4. Koletzko S, Jones NL, Goodman KJ, et al. Evidence-based guidelines from ESPGHAN and NASPGHAN for Helicobacter pylori infection in children. J Pediatr Gastroenterol Nutr. 2011;53(2):230-43.

5. Hooi JKY, Lai WY, Ng WK, et al. Global prevalence of Helicobacter pylori infection: systematic review and meta-analysis. Gastroenterology. 2017;153(2):420-9.

6. Zabala Torrres B, Lucero Y, Lagomarcino AJ, et al. Review: prevalence and dynamics of Helicobacter pylori infection during childhood. Helicobacter. 2017;22(5):e12399.

7. Zamani M, Ebrahimtabar F, Zamani V, et al. Systematic review with meta-analysis: the worldwide prevalence of Helicobacter pylori infection. Aliment Pharmacol Ther. 2018;47(7):868-76.

8. Asgeirsdottir GA, Kjartansdottir I, Olafsdottir AS, et al. Helicobacter pylori infection in Icelandic children. Scand J Gastroenterol. 2017;52(6-7):686-90.

9. Mana F, Vandebosch S, Miendje Deyi V, Haentjens P, Urbain D. Prevalence of and risk factors for $H$. pylori infection in healthy children and young adults in Belgium anno 2010/2011. Acta Gastroenterol Belg. 2013;76(4):381-5.

10. Biernat MM, Iwańczak B, Bińkowska A, Grabińska J, Gościniak G. The prevalence of Helicobacter pylori infection in symptomatic children: a 13-year observational study in the Lower Silesian region. Adv Clin Exp Med. 2016;25(2):303-8.

11. Daugule I, Karklina D, Rudzite D, Remberga S, RumbaRozenfelde I. Prevalence of Helicobacter pylori infection among preschool children in Latvia: no significant decrease in prevalence during a 10 years period. Scand J Public Health. 2016;44(4):418-22.

12. Kusano C, Gotoda T, Ishikawa H, Moriyama M. The administrative project of Helicobacter pylori infection screening among junior high school students in an area of Japan with a high incidence of gastric cancer. Gastric Cancer. 2017;20(Suppl 1):16-9.

13. Nakayama Y, Lin Y, Hongo M, Hidaka H, Kikuchi S. Helicobacter pylori infection and its related factors in junior high school students in Nagano Prefecture, Japan. Helicobacter. 2017;22(2):e12363. 
14. Moosazadeh M, Lankarani KB, Afshari M. Meta-analysis of the prevalence of Helicobacter pylori infection among children and adults of Iran. Int J Prev Med. 2016;7(1):48.

15. Shu X, Ping M, Yin G, Jiang M. Investigation of Helicobacter pylori infection among symptomatic children in Hangzhou from 2007 to 2014: a retrospective study with 12,796 cases. PeerJ. 2017;5(Suppl 1):e2937.

16. Nguyen TVH, Nguyen VB, Binh Phan TT, Hoang Ha TT. Epidemiology of Helicobacter pylori infection in tay children in Vietnam. Ann Clin Lab Res. 2016;04(04):1-22.

17. Abdul Rahim NR, Benson J, Grocke K, et al. Prevalence of Helicobacter pylori infection in newly arrived refugees attending the Migrant Health Service, South Australia. Helicobacter. 2016;22(2):e12360.

18. Morais S, Costa AR, Ferro A, Lunet N, Peleteiro B. Contemporary migration patterns in the prevalence of Helicobacter pylori infection: a systematic review. Helicobacter. 2017;22(3):e12372.

19. Awuku YA, Simpong DL, Alhassan IK, Tuoyire DA, Afaa T, Adu P. Prevalence of Helicobacter pylori infection among children living in a rural setting in Sub-Saharan Africa. BMC Public Health. 2017;17(1):360.

20. Castro-Muñoz LJ, González-Díaz CA, Muñoz-Escobar A, et al. Prevalence of Helicobacter pylori from the oral cavity of Mexican asymptomatic children under 5 years of age through PCR. Arch Oral Biol. 2017;73:55-9.

21. Ortiz-Princz D, Daoud G, Salgado-Sabel A, Cavazza ME. Helicobacter pylori infection in children: should it be carefully assessed? Eur Rev Med Pharmacol Sci. 2016;20(9):1798-813.

22. Salimzadeh L, Bagheri N, Zamanzad B, et al. Frequency of virulence factors in Helicobacter pylori-infected patients with gastritis. Microb Pathog. 2015;80:67-72.

23. Alzahrani S, Lina TT, Gonzalez J, Pinchuk IV, Beswick EJ, Reyes VE. Effect of Helicobacter pylori on gastric epithelial cells. World J Gastroenterol. 2014;20(36):12767-80.

24. Wroblewski LE, Peek RM. Helicobacter pylori in gastric carcinogenesis: mechanisms. Gastroenterol Clin North Am. 2013;42(2):285-98.

25. Serrano C, Wright SW, Bimczok D, et al. Downregulated Th17 responses are associated with reduced gastritis in Helicobacter pylori-infected children. Mucosal Immunol. 2013;6(5):950-9.

26. Harris PR, Smythies LE, Smith PD, Perez-Perez GI. Role of childhood infection in the sequelae of $H$. pylori disease. Gut Microbes. 2013;4(6):426-38.

27. Bontems P, Robert F, Van Gossum A, Cadranel S, Mascart F. Helicobacter pylori modulation of gastric and duodenal mucosal $\mathrm{T}$ cell cytokine secretions in children compared with adults. Helicobacter. 2003;8(3):216-26.

28. Harris PR, Wright SW, Serrano C, et al. Helicobacter pylori gastritis in children is associated with a regulatory T-cell response. Gastroenterology. 2008;134(2):491-9.

29. D'Elios MM, Manghetti M, De Carli M, et al. T helper 1 effector cells specific for Helicobacter pylori in the gastric antrum of patients with peptic ulcer disease. J Immunol. 1997;158(2):962-7.

30. Razavi A, Bagheri N, Azadegan-Dehkordi F, et al. Comparative immune response in children and adults with $H$. pylori infection. J Immunol Res. 2015;2015(3):315957-60.

31. Mărginean MO, Mărginean CO, Meliţ LE, Voidăzan S, Moldovan V, Bănescu C. The impact of host's genetic susceptibility on Helicobacter pylori infection in children. Medicine (Baltimore). 2017;96(30):e7612.

32. Saes M, de Labio RW, Rasmussen LT, Payão SLM. Interleukin $8(-251 \mathrm{~T}>\mathrm{A})$ polymorphism in children and teenagers infected with Helicobacter pylori. J Venom Anim Toxins Incl Trop Dis. 2017;23(1):23.
33. Michalkiewicz J, Helmin-Basa A, Grzywa R, et al. Innate immunity components and cytokines in gastric mucosa in children with Helicobacter pylori infection. Mediators Inflamm. 2015;2015(5):176726-7.

34. Brawner KM, Kumar R, Serrano CA, et al. Helicobacter pylori infection is associated with an altered gastric microbiota in children. Mucosal Immunol. 2017;10(5):1169-77.

35. McColl K, Murray L, El-Omar E, et al. Symptomatic benefit from eradicating Helicobacter pylori infection in patients with nonulcer dyspepsia. N Engl J Med. 1998;339(26):1869-74.

36. Moayyedi P, Deeks J, Talley NJ, Delaney B, Forman D. An update of the cochrane systematic review of Helicobacter pylori eradication therapy in nonulcer dyspepsia: resolving the discrepancy between systematic reviews. Am J Gastroenterol. 2003;98(12):2621-6.

37. Moayyedi P, Soo S, Deeks J, et al. Eradication of Helicobacter pylori for non-ulcer dyspepsia. Cochrane Database Syst Rev. 2006;66(2):002096.

38. Oderda G, Dell'Olio D, Morra I, Ansaldi N. Campylobacter pylori gastritis: long term results of treatment with amoxycillin. Arch Dis Child. 1989;64(3):326-9.

39. De Giacomo C, Fiocca R, Villani L, et al. Helicobacter pylori infection and chronic gastritis: clinical, serological, and histologic correlations in children treated with amoxicillin and colloidal bismuth subcitrate. J Pediatr Gastroenterol Nutr. 1990;11(3):310-6.

40. Shamaly H, Berkowitz D, Rosenthal E, Naveh Y. Efficacy of bismuth-based triple therapy in children with abdominal pain and Helicobacter pylori gastritis. J Pediatr Gastroenterol Nutr. 2000;30(2):198-200.

41. Frank F, Stricker T, Stallmach T, Braegger CP. Helicobacter pylori infection in recurrent abdominal pain. J Pediatr Gastroenterol Nutr. 2000;31(4):424-7.

42. Shashidhar H, Peters J, Lin CH, Rabah R, Thomas R, Tolia V. A prospective trial of lansoprazole triple therapy for pediatric Helicobacter pylori infection. J Pediatr Gastroenterol Nutr. 2000;30(3):276-82.

43. Ozen H, Dinler G, Akyön Y, Koçak N, Yüce A, Gürakan F. Helicobacter pylori infection and recurrent abdominal pain in Turkish children. Helicobacter. 2001;6(3):234-8.

44. Uc A, Chong SKF. Treatment of Helicobacter pylori gastritis improves dyspeptic symptoms in children. J Pediatr Gastroenterol Nutr. 2002;34(3):281-5.

45. Farrell S, Milliken I, Murphy JL, Wootton SA, McCallion WA. Nonulcer dyspepsia and Helicobacter pylori eradication in children. J Pediatr Surg. 2005;40(10):1547-50.

46. Ashorn M, Rägö T, Kokkonen J, Ruuska T, Rautelin H, Karikoski R. Symptomatic response to Helicobacter pylori eradication in children with recurrent abdominal pain: double blind randomized placebo-controlled trial. J Clin Gastroenterol. 2004;38(8):646-50.

47. Hyams JS, Di Lorenzo C, Saps M, Shulman RJ, Staiano A, van Tilburg M. Childhood functional gastrointestinal disorders: child/adolescent. Gastroenterology. 2016;150(6):1456-68.

48. Romano C, Valenti S, Cardile S, Benninga MA. Functional dyspepsia. J Pediatr Gastroenterol Nutr. 2016;63(6):579-84.

49. Alimohammadi H, Fouladi N, Salehzadeh F, Alipour SA, Javadi MS. Childhood recurrent abdominal pain and Helicobacter pylori infection, Islamic Republic of Iran. East Mediterr Health J. 2017;22(12):860-4.

50. Correa Silva RGS, Machado NC, Carvalho MA, Rodrigues MAM. Helicobacter pylori infection is high in paediatric nonulcer dyspepsia but not associated with specific gastrointestinal symptoms. Acta Paediatr. 2016;105(5):e228-31.

51. Sykora J, Huml M, Siala K, et al. Paediatric Rome III criteriarelated abdominal pain is associated with Helicobacter pylori 
and not with calprotectin. J Pediatr Gastroenterol Nutr. 2016;63(4):417-22.

52. Koca T, Serdaroglu F, Dereci S, Akcam M. Peptic ulcers and erosions in children at a pediatric unit in Turkey. Indian Pediatr. 2016;53(8):692-4.

53. Erdemir G, Ozkan TB, Ozgur T, Altay D, Cavun S, Goral G. Helicobacter pylori infection in children: nutritional status and associations with serum leptin, ghrelin, and IGF-1 levels. Helicobacter. 2016;21(4):317-24.

54. Romo-González C, Mendoza E, Mera RM, et al. Helicobacter pylori infection and serum leptin, obestatin, and ghrelin levels in Mexican schoolchildren. Pediatr Res. 2017;82(4):607-13.

55. Queiroz DMM, Rocha AMC, Crabtree JE. Unintended consequences of Helicobacter pylori infection in children in developing countries: iron deficiency, diarrhea, and growth retardation. Gut Microbes. 2013;4(6):494-504.

56. Wang M. Iron deficiency and other types of anemia in infants and children. Am Fam Physician. 2016;93(4):270-8.

57. Pacifico L, Osborn JF, Tromba V, Romaggioli S, Bascetta S, Chiesa C. Helicobacter pylori infection and extragastric disorders in children: a critical update. World J Gastroenterol. 2014;20(6):1379-401.

58. Muhsen K, Cohen D. Helicobacter pylori infection and iron stores: a systematic review and meta-analysis. Helicobacter. 2008;13(5):323-40.

59. Qu X-H, Huang X-L, Xiong P, et al. Does Helicobacter pylori infection play a role in iron deficiency anemia? A meta-analysis. World J Gastroenterol. 2010;16(7):886-96.

60. Huang X, Qu X, Yan W, et al. Iron deficiency anaemia can be improved after eradication of Helicobacter pylori. Postgrad Med J. 1015;2010(86):272-8.

61. Yuan W, Yumin Li, Kehu Yang, et al. Iron deficiency anemia in Helicobacter pylori infection: meta-analysis of randomized controlled trials. Scand J Gastroenterol. 2010;45(6):665-76.

62. Hudak L, Jaraisy A, Haj S, Muhsen K. An updated systematic review and meta-analysis on the association between Helicobacter pylori infection and iron deficiency anemia. Helicobacter. 2017;22(1):e12330.

63. Palau J, Jarque I, Sanz MA. Long-term management of chronic immune thrombocytopenic purpura in adults. Int J Gen Med. 2010;3:305-11.

64. Weber E, Reynaud Q, Fort R, et al. Immunomodulatory treatments for persistent and chronic immune thrombocytopenic purpura: a PRISMA-compliant systematic review and metaanalysis of 28 studies. Medicine (Baltimore). 2017;96(37):e7534.

65. Jackson S, Beck PL, Pineo GF, Poon M-C. Helicobacter pylori eradication: novel therapy for immune thrombocytopenic purpura? A review of the literature. Am J Hematol. 2005;78(2):142-50.

66. Franchini M, Cruciani M, Mengoli C, Pizzolo G, Veneri D. Effect of Helicobacter pylori eradication on platelet count in idiopathic thrombocytopenic purpura: a systematic review and meta-analysis. J Antimicrob Chemother. 2007;60(2):237-46.

67. Arnold DM, Stasi R. Does Helicobacter pylori eradication therapy result in a platelet count improvement in adults with immune thrombocytopenic purpura regardless of $H$. pylori infection? ASH evidence-based review 2008. Hematology. 2008;2008(1):31-2.

68. Stasi R, Sarpatwari A, Segal JB, et al. Effects of eradication of Helicobacter pylori infection in patients with immune thrombocytopenic purpura: a systematic review. Blood. 2009;113(6):1231-40.

69. Franchini M, Vescovi P, Garofano M, Veneri D. Helicobacter Pylori-associated idiopathic thrombocytopenic purpura: a narrative review. Semin Thromb Hemost. 2012;38(05):463-8.
70. Dror G, Muhsen K. Helicobacter pylori infection and children's growth: an overview. J Pediatr Gastroenterol Nutr. 2016;62(6):e48-59.

71. Taye B, Enquselassie F, Tsegaye A, et al. Effect of Helicobacter pylori infection on growth trajectories in young Ethiopian children: a longitudinal study. Int J Infect Dis. 2016;50:57-66.

72. Xiong L-J, Mao M. Current views of the relationship between Helicobacter pylori and Henoch-Schonlein purpura in children. World J Clin Pediatr. 2016;5(1):82-8.

73. Wasilewska J, Klukowski M, Debkowska K, et al. Helicobacter pylori seroprevalence in children with sleep-disordered breathing. Int J Pediatr Otorhinolaryngol. 2016;87:208-12.

74. Bazmamoun H, Rafeey M, Nikpouri M, Ghergherehchi R. Helicobacter pylori infection in children with type 1 diabetes mellitus: a case-control study. J Res Health Sci. 2016;16(2):68-71.

75. Osman SM, Mubarak SM, Omer IM, Abdullah MA. Helicobacter pylori infection and the onset of type 1 diabetes mellitus in Sudanese children. Sudan J Paediatr. 2016;16(2):59-66.

76. Arnold IC, Hitzler I, Müller A. The immunomodulatory properties of Helicobacter pylori confer protection against allergic and chronic inflammatory disorders. Front Cell Infect Microbiol. 2012;2:10.

77. den Hollander WJ, Sonnenschein-van der Voort AMM, Holster IL, et al. Helicobacter pylori in children with asthmatic conditions at school age, and their mothers. Aliment Pharmacol Ther. 2016;43(8):933-43.

78. Czaja-Bulsa G, Bulsa M, Gębala A. Food IgG4 antibodies are elevated not only in children with wheat allergy but also in children with gastrointestinal diseases. BMC Gastroenterol. 2016;16(1):39.

79. Narang M, Puri AS, Sachdeva S, Singh J, Kumar A, Saran RK. Celiac disease and Helicobacter pylori infection in children: Is there any association? J Gastroenterol Hepatol. 2017;32(6):1178-82.

80. Yang HR. Updates on the diagnosis of Helicobacter pylori infection in children: what are the differences between adults and children? Pediatr Gastroenterol Hepatol Nutr. 2016;19(2):96-103.

81. Lash RH, Genta RM. Routine anti-helicobacter immunohistochemical staining is significantly superior to reflex staining protocols for the detection of Helicobacter in gastric biopsy specimens. Helicobacter. 2016;21(6):581-5.

82. Leal YA, Flores LL, Fuentes-Pananá EM, Cedillo-Rivera R, Torres J. 13C-urea breath test for the diagnosis of Helicobacter pylori infection in children: a systematic review and metaanalysis. Helicobacter. 2011;16(4):327-37.

83. Honar N, Minazadeh A, Shakibazad N, Haghighat M, Saki F, Javaherizadeh H. Diagnostic accuracy of urea breath test for Helicobacter pylori infection in children with dyspepsia in comparison to histopathology. Arq Gastroenterol. 2016;53(2):108-12.

84. George S, Mamani N, Lucero Y, et al. Detection of Helicobacter pylori by real-time PCR for $16 \mathrm{~s}$ rRNA in stools of noninfected healthy children, using ELISA antigen stool test as the gold standard. Helicobacter. 2016;21(6):606-12.

85. Kalach N, Gosset P, Dehecq E, et al. Usefulness of gastric biopsy-based real-time polymerase chain reaction for the diagnosis of Helicobacter pylori infection in children. J Pediatr Gastroenterol Nutr. 2015;61(3):307-12.

86. Kalach N, Gosset P, Dehecq E, et al. A one-step immunechromatographic Helicobacter pylori stool antigen test for children was quick, consistent, reliable and specific. Acta Paediatr. 2017;106(12):2025-30.

87. Shady MMA, Fathy HA, Ali A, Galal EM, Fathy GA, Sibaii H. Comparison of serum IgG antibody test with gastric biopsy for 
the detection of Helicobacter pylori infection among Egyptian children. Open Access Maced J Med Sci. 2015;3(2):303-6.

88. Mabe K, Kikuchi S, Okuda M, Takamasa M, Kato M, Asaka M. Diagnostic accuracy of urine Helicobacter pylori antibody test in junior and senior high school students in Japan. Helicobacter. 2017;22(1):e12329.

89. Seo J-H, Lim CW, Park JS, et al. Correlations between the CagA antigen and serum levels of anti-Helicobacter pylori $\mathrm{IgG}$ and IgA in children. J Korean Med Sci. 2016;31(3):417-22.

90. Raj P, Thompson JF, Pan DH. Helicobacter pylori serology testing is a useful diagnostic screening tool for symptomatic inner city children. Acta Paediatr. 2017;106(3):470-7.

91. Bayrakli I, Turkmen A, Cem Kockar M. Feasibility study of using breath ammonia analysis based on off-axis cavity-enhanced absorption spectroscopy with external cavity diode laser for noninvasive real-time diagnosis of Helicobacter pylori. Appl Spectrosc. 2016;70(8):1269-77.

92. Graham DY, Fischbach L. Helicobacter pylori treatment in the era of increasing antibiotic resistance. Gut. 2010;59(8):1143-53.

93. Graham DY, Lee Y-C, Wu M-S. Rational Helicobacter pylori therapy: evidence-based medicine rather than medicine-based evidence. Clin Gastroenterol Hepatol. 2014;12(2):177-86.

94. Huang Y, Zhan X. Sequential therapy is superior to triple therapy for Helicobacter pylori infection in children: a metaanalysis. Indian J Pediatr. 2016;83(4):307-15.

95. Vakil N. H. pylori treatment: new wine in old bottles? Am J Gastroenterol. 2009;104(1):26-30.

96. Malfertheiner P, Megraud F, O’Morain CA, et al. Management of Helicobacter pylori infection-the Maastricht IV/florence consensus report. London: BMJ Publishing Group Ltd and British Society of Gastroenterology; 2012. p. 646-64.

97. Fuccio L, Minardi ME, Zagari RM, Grilli D, Magrini N, Bazzoli F. Meta-analysis: duration of first-line proton-pump inhibitor based triple therapy for Helicobacter pylori eradication. Ann Intern Med. 2007;147(8):553-62.

98. Yuan Y, Ford AC, Khan KJ, et al. Optimum duration of regimens for Helicobacter pylori eradication. Cochrane Database Syst Rev. 2013;61(12):008337.

99. Oderda G, Shcherbakov P, Bontems P, et al. Results from the pediatric European register for treatment of Helicobacter pylori (PERTH). Helicobacter. 2007;12(2):150-6.

100. Francavilla R, Lionetti E, Castellaneta SP, et al. Improved efficacy of 10-day sequential treatment for Helicobacter pylori eradication in children: a randomized trial. Gastroenterology. 2005;129(5):1414-9.

101. Horvath A, Dziechciarz P, Szajewska H. Letter: sequential therapy for Helicobacter pylori eradication in children' updated meta-analysis of randomized controlled trials. Aliment Pharmacol Ther. 2013;37(8):835-6.

102. Tong JL, Ran ZH, Shen J, Xiao SD. Sequential therapy vs. standard triple therapies for Helicobacter pylori infection: a meta-analysis. J Clin Pharm Ther. 2009;34(1):41-53.

103. Sustmann A, Okuda M, Koletzko S. Helicobacter pylori in children. Helicobacter. 2016;21(S1):49-54.

104. Kotilea K, Mekhael J, Salame A, et al. Eradication rate of Helicobacter pylori infection is directly influenced by adherence to therapy in children. Helicobacter. 2017;53(4):e12383.

105. Malfertheiner P, Megraud F, O'Morain CA, et al. Management of Helicobacter pylori infection-the Maastricht V/florence consensus report. Gut. 2017;66(1):6-30.

106. Malfertheiner P, Bazzoli F, Delchier J-C, et al. Helicobacter pylori eradication with a capsule containing bismuth subcitrate potassium, metronidazole, and tetracycline given with omeprazole versus clarithromycin-based triple therapy: a randomised, open-label, non-inferiority, phase 3 trial. Lancet. 2011;377(9769):905-13.
107. Walsh D, Goggin N, Rowland M, Durnin M, Moriarty S, Drumm B. One week treatment for Helicobacter pylori infection. Arch Dis Child. 1997;76(4):352-5.

108. Hong J, Yang HR. Efficacy of proton pump inhibitor-based triple therapy and bismuth-based quadruple therapy for Helicobacter pylori eradication in Korean children. Pediatr Gastroenterol Hepatol Nutr. 2012;15(4):237-42.

109. de Oliveira Andrade D, Bontems P, Corvaglia L, Scaillon M, Cadranel S. Increasing resistance of Helicobacter pylori to antibiotics: usefulness of culture and antibiograms. J Pediatr Gastroenterol Nutr. 1996;22:431 (Abstract).

110. Bontems P, Devaster JM, Corvaglia L, et al. Twelve year observation of primary and secondary antibiotic-resistant Helicobacter pylori strains in children. Pediatr Infect Dis J. 2001;20(11):1033-8.

111. Miendje Deyi VY, Bontems P, Vanderpas J, et al. Multicenter survey of routine determinations of resistance of Helicobacter pylori to antimicrobials over the last 20 years (1990-2009) in Belgium. J Clin Microbiol. 2011;49(6):2200-9.

112. Lare MS, Bontems P, Elkilic O, et al. Update of primary Helicobacter pylori resistance to antimicrobials in Brussels. Helicobacter. 2017;22(Suppl 1):58-9 (abstract).

113. Gościniak G, Biernat MM, Bińkowska A, Kus A, Iwańczak B. Frequency of infection with Helicobacter pylori isolates of different antimicrobial profiles in children and adolescents: a preliminary study. Adv Clin Exp Med. 2017;26(2):263-8.

114. Montes M, Villalon FN, Eizaguirre FJ, et al. Helicobacter pylori infection in children. Antimicrobial resistance and treatment response. Helicobacter. 2015;20(3):169-75.

115. Manfredi M, Gismondi P, Maffini V, et al. Primary antimicrobial susceptibility changes in children with Helicobacter pylori infection over 13 years in Northern Italy. Gastroenterol Res Pract. 2015;2015(8):717349-50.

116. Maleknejad S, Mojtahedi A, Safaei-Asl A, Taghavi Z, Kazemnejad E. Primary antibiotic resistance to Helicobacter pylori strains isolated from children in Northern Iran: a single center study. Iran J Pediatr. 2015;25(6):e2661.

117. Regnath $\mathrm{T}$, Raecke $\mathrm{O}$, Enninger A, Ignatius $\mathrm{R}$. Increasing metronidazole and rifampicin resistance of Helicobacter pylori isolates obtained from children and adolescents between 2002 and 2015 in southwest Germany. Helicobacter. 2017;22(1):e12327.

118. Aguilera-Correa JJ, Urruzuno P, Barrio J, et al. Detection of Helicobacter pylori and the genotypes of resistance to clarithromycin and the heterogeneous genotype to this antibiotic in biopsies obtained from symptomatic children. Diagn Microbiol Infect Dis. 2017;87(2):150-3.

119. Mahmoudi S, Mamishi S, Banar M, et al. Antibiotic susceptibility of Helicobacter pylori strains isolated from Iranian children: high frequency of $\mathrm{A} 2143 \mathrm{G}$ point mutation associated with clarithromycin resistance. J Glob Antimicrob Resist. 2017;10:131-5.

120. Khoury J, Geffen Y, Shaul R, Sholy H, Chowers Y, Saadi T. Secondary antibiotic resistance of Helicobacter pylori isolates in Israeli children and adults. J Glob Antimicrob Resist. 2017;10:182-5.

121. Ogata SK, Gales AC, Kawakami E. Antimicrobial susceptibility testing for Helicobacter pylori isolates from Brazilian children and adolescents: comparing agar dilution, $E$ test, and disk diffusion. Braz J Microbiol. 2014;45(4):1439-48.

122. Weiner N, Shaoul R. Impact of age, gender, and addition of probiotics on treatment success for Helicobacter pylori in children. Glob Pediatr Health. 2015;2:2333794X15607798.

123. Ramos-Soriano AG, Black J. Nitazoxanide use as part of an empiric multi-drug regimen in treating children with suspected 
Helicobacter pylori infection. Case Rep Gastroenterol. 2015;9(1):36-42.

124. Esmaeili-Dooki MR, Shirdel H, Hajiahmadi M. Eradication of Helicobacter pylori in children by triple therapy regimens of amoxicillin, omeprazole, and clarithromycin or azithromycin. Iran J Pediatr. 2015;25(6):e2360.

125. Farahmand F, Mohammadi T, Najafi M, et al. Comparison of ciprofloxacin-based triple therapy with conventional triple regimen for Helicobacter pylori eradication in children. Acta Med Iran. 2016;54(6):395-400.

126. Iwańczak BM, Borys-Iwanicka A, Biernat M, Gościniak G. Assessment of sequential and standard triple therapy in treatment of Helicobacter pylori infection in children dependent on bacteria sensitivity to antibiotics. Adv Clin Exp Med. 2016;25(4):701-8.

127. Butenko T, Jeverica S, Orel R, Homan M. Antibacterial resistance and the success of tailored triple therapy in Helicobacter pylori strains isolated from Slovenian children. Helicobacter. 2017;22(5):e12400.

128. Hurduc V, Plesca D, Dragomir D, Sajin M, Vandenplas Y. A randomized, open trial evaluating the effect of Saccharomyces boulardii on the eradication rate of Helicobacter pylori infection in children. Acta Paediatr. 2009;98(1):127-31.

129. Szajewska H, Horvath A, Piwowarczyk A. Meta-analysis: the effects of Saccharomyces boulardii supplementation on Helicobacter pylori eradication rates and side effects during treatment. Aliment Pharmacol Ther. 2010;32(9):1069-79.
130. Zhang W, Chen Q, Liang X, et al. Bismuth, lansoprazole, amoxicillin and metronidazole or clarithromycin as first-line Helicobacter pylori therapy. Gut. 2015;64(11):1715-20.

131. Lionetti E, Miniello VL, Castellaneta SP, et al. Lactobacillus reuteri therapy to reduce side-effects during anti-Helicobacter pylori treatment in children: a randomized placebo controlled trial. Aliment Pharmacol Ther. 2006;24(10):1461-8.

132. Sykora J, Valecková K, Amlerová J, et al. Effects of a specially designed fermented milk product containing probiotic Lactobacillus casei $\mathrm{DN}-114001$ and the eradication of $\mathrm{H}$. pylori in children: a prospective randomized double-blind study. J Clin Gastroenterol. 2005;39(8):692-8.

133. Wang Y-H, Huang Y. Effect of Lactobacillus acidophilus and Bifidobacterium bifidum supplementation to standard triple therapy on Helicobacter pylori eradication and dynamic changes in intestinal flora. World $\mathrm{J}$ Microbiol Biotechnol. 2014;30(3):847-53.

134. Cruchet S, Furnes R, Maruy A, et al. The use of probiotics in pediatric gastroenterology: a review of the literature and recommendations by Latin-American experts. Paediatr Drugs. 2015;17(3):199-216.

135. Lau C, Ward A, Chamberlain R. Probiotics improve the efficacy of standard triple therapy in the eradication of Helicobacter pylori: a meta-analysis. Infect Drug Resist. 2016;9:275-89.

136. Feng J-R, Wang F, Qiu X, et al. Efficacy and safety of probioticsupplemented triple therapy for eradication of Helicobacter pylori in children: a systematic review and network meta-analysis. Eur J Clin Pharmacol. 2017;73(10):1199-208. 